\title{
Design and Implementation of Micro-Project Learning in Furnishing Curriculum of College
}

\author{
Siyi Jia
}

Guangxi Arts University,Nanning 530000,China

\begin{abstract}
In view of the specific problems in the current furnishings curriculum, combined with the understanding of various "Micro" concepts such as project learning, micro-resources and micro-classrooms, overcoming the original shortcomings of project learning, and proposing "Micro Project" concept."Micro-project learning" is essentially the flexible use of project learning, which makes project learning simplified and miniaturized, making classroom learning more efficient, flexible and practical.This thesis expounds the specific methods and advantages of micro-project learning, and has made a series of teaching design, which realizes the application of micro-project learning in the teaching of college furnishings, and improves the teaching effect.
\end{abstract}

Keywords: Micro-Project Learning; Furnishings Curriculum; Design; Implementation

COPYRIGHT

Copyright (C) 2019 by author(s) and

Frontier Scientific Publishing. This work is

licensed under the Creative Commons

Attribution-NonCommercial 4.0

International License (CC BY-NC 4.0).

$\mathrm{http}: / /$ creativecommons.org/licenses/

\section{Analysis of the current situation of teaching in furnishings curriculum}

Furnishing design is an emerging project in the Chinese art design industry. The demand for talents in the market is very huge. Many colleges and universities have also opened the design of furnishings curriculum or the introduction of furnishings curriculum. At present, the content requirements of college furnishings curriculum have high applicability and operability, but the development history of furnishings is short and there is no corresponding foundation accumulation, which makes the difficulty of such curriculum in teaching.The purpose of the teaching of the furnishings curriculum is to train the students' ability to design the furnishings in the actual operation through the teaching of the content of the textbooks, to exercise their skills in setting up the real room, and to improve the space for multiple artistic design thinking.Take the "Environmental Furnishing Design" curriculum of our institute as an example,this course was opened in 2006, but most teachers used the "project introduction classroom" to be teaching method.The "project introduction classroom" method has accumulated its own unique advantages and practical experience in the long-term social design practice, and has been highly praised by teachers and has been promoted and used. However, with the advent of the Internet era, teachers have become more and more aware that the students who born after 2000 have little interest in this traditional teaching method, and they appreciate personality. The design perspective, the more flat approach to practice, and the increasing interest in classroom fun and visuality. The teaching method based on "project introduction into the classroom" originally had shortcomings such as low student participation and large social and classroom spans. It is can not meet the requirements of students.In order to improve the quality of teaching, we should change the classroom teaching form, encourage students to choose their own points of interest, and then improve their motivation and exploration ability, so as to realize the students' future design ability. 


\section{Specific methods and advantages of micro-project learning}

Micro-project learning: Micro Project is the miniaturization and simplification of the project; micro-project learning is essentially the flexible use of project learning, combining the concepts of project learning and micro-courses. This teaching method overcomes the "project into the classroom, the shortcomings retain its advantages. The overall learning process is to divide the entire knowledge into a number of micro-refined knowledge surfaces, to achieve students' precise management of knowledge and content, and to improve teaching flexibility.

Micro-project learning starts with small projects designed by furnishings. Each project has a complete design process. In the learning process, it usually takes only $2-8$ hours. The project content is usually related to the design or complete operation of a small space. Micro-projects simplify the complex and large-scale space during design, allowing students to master the design ability while eliminating unnecessary operations that can be disturbed, so as to more accurately grasp the design points. While constantly mastering the knowledge points, it also strengthens the cooperation and discussion between students and students, between teachers and students, and realizes the sharing of knowledge.

\section{The Design and Implementation of Micro-Project Learning}

The micro-project teaching design is divided into six stages: micro-project selection, planning, group exploration, achievement completion, display reporting, evaluation and acceptance.

Micro-project selection: In micro-project learning, micro-project theme and volume selection are crucial, considering both $\mathrm{m}$ knowledge points and project completion, as well as students' knowledge base.The selected micro-projects should not only cover the key points and objectives of the course knowledge, but also should be selected according to the students' professional ability and school professional characteristics, and choose 1-3 students to complete.

Planning: The group is divided into groups by heterogeneous grouping. Each group makes systematic planning to ensure that the group members' interests, abilities and strengths can be fully demonstrated. Combined with the design tasks of the micro-projects, the team members and the design stage are carried out. A reasonable division of labor ensures that micro-project tasks can be completed qualitatively andquantitatively.

Group inquiry: This stage is the most important stage in micro-project learning. The grouping standard is "project theme".In order to achieve the micro-project learning objectives, the team members should strengthen the sense of cooperation and discussion depth, and promote the completion of learning development and micro-project tasks.In this process, the teacher should do a good job of guiding and correcting the work, and control the learning process and progress of the group. When the group encounters difficulties, the teacher should promptly answer questions and make demonstrations to provide guarantee for the smooth development of the micro-project.To a certain extent, the teacher is not a mere knowledge spreader, but is an explorer and learner like a student. Therefore, a mutual interaction and mutual promotion community has been formed between the teacher and the student. Collaborative learning between teachers and students.

Completion of results: In the micro-project learning, the team's efforts to implement the knowledge points, independent and appropriate innovation of the design works into the real or actual space, which is an important feature of micro-project learning is different from the traditional classroom teaching methods. At this stage, the teacher must control the depth and flexibility of guiding participation. In order to complete the progress and quality of the project results, the teacher should organize the team to report the progress of the work publicly after a small stage, guide the team to complete the tasks in the course of the task, and provide opinions and suggestions.

Display report: This stage is mainly the public presentation of the project results of each group. It can be displayed between teachers and students, and can also be displayed to the whole school or even more to share the experience and experience in the process of completing the micro project results. In this stage, it mainly displays the design and creative points, the landing process and regrets of the design works of this group, and provides other groups with opportunities for learning and reference, and also prepares for the implementation of the second micro-project of the group. 
Evaluation and acceptance: In the whole micro-project learning process, teachers should do a formative evaluation and a summary evaluation.In each group learning process, according to the student's task division completion and completion quality, qualitative evaluation, quantitative evaluation, and overall evaluation of the group and independent individual evaluation of students should be done.At the same time, students should also learn from teachers and feedback to learn from them and increase their experience.

\section{Furnishings design in Porch of House" Micro-Project Teaching Case Implementation}

This micro-project belongs to the teaching module of the environmental design curriculum. The preliminary preparation is the basic design of the 16-hours design.In the first semester of the 2018-2019 "Environmental Furnishing Design" course, which set 1 person for the main instructor ,and 2 person for deputy guidance teachers.This micro project takes 6 class hours.

\subsection{Six stages of micro-project teaching}

\subsubsection{Selection of this micro project:}

A. Design site: the entrance space of a commercial house near the school, 3 meters open, 2 meters deep, 2.8 meters high. B. The theme question bank selected by the teacher is: the aesthetics of traditional architectural decoration in southern China. The sub-themes selected by the student group mainly include: The aesthetics of Buddhist architectural decoration in Guiping, Guangxi; The architectural aesthetics of residential buildings in Jiangnan; Guangxi Huashan Decorative aesthetics; Lingnan squatter decoration aesthetics; Yunnan Hani mushroom house architectural decoration aesthetics. C. Requirements: The decorative materials are as simple as possible. The selection of furnishings is: 1 table, 3-5 table decorations, 1-2 kinds of wallpapers, 1-2 kinds of wall decorations, some green flowers, etc. The total market price budget does not exceed 5000 yuan.

\subsubsection{Planning}

One group of 1-3 students, each group has 1 team leader and at least 1 software draftsman. The team leader is responsible for the reasonable allocation and recording of the work of the team members, and timely feedback to the teachers on the progress of the work and the problems encountered during the process.

\subsubsection{Group inquiry:}

Divided into five stages: main design, sub-version design, rendering design, sample or model making, and physical production (optional).As shown in Table 1.

\subsubsection{The results :}

The main version and the secondary version of the paper version, one half open specifications. The renderings can be selected electronically or in hand-painted paper. Samples, models, and objects are produced by the teams in their own right proportions.

\subsubsection{Display and Report:}

A report exhibition will be held on campus, with 3 instructors responsible for the exhibition and development. In the exhibition: A. Each group introduces the work (10 minutes); B. each group makes suggestions and questions to other groups (20 minutes); C. the instructor responds (5 minutes each).

\subsubsection{Evaluation and Acceptance:}

The instructor team will conduct a targeted and timely evaluation of each group, including formative evaluation, summative evaluation, qualitative evaluation, quantitative evaluation, and overall evaluation of the group and independent students. Evaluation.In addition, in the performance evaluation, four levels are set for the acceptance of 
the design work, so that the students know that the winner is.As shown in Table 1.

\begin{tabular}{|c|c|c|}
\hline & Teacher & Student/group \\
\hline $\begin{array}{l}\text { Micro } \\
\text { project } \\
\text { selection }\end{array}$ & $\begin{array}{l}\text { A design theme question bank is } \\
\text { selected by the teacher. }\end{array}$ & Co-deliberation, Select subtopics in the question bank \\
\hline $\begin{array}{l}\text { Group } \\
\text { inquiry }\end{array}$ & $\begin{array}{l}\text { Provide excellent design cases, provide } \\
\text { protection, and collaborative learning. }\end{array}$ & $\begin{array}{l}\text { 1. Group by yourself, } 1 \text { person is responsible for the main } \\
\text { version, } \\
2 \text { people are responsible for the vice version. Take } 2 \text { class } \\
\text { hours; } \\
2,1 \text { person is responsible for the renderings, } 2 \text { people are } \\
\text { responsible for the sample or model or physical production. } \\
\text { Accounted for } 4 \text { Class hours. }\end{array}$ \\
\hline $\begin{array}{l}\text { Display } \\
\text { report }\end{array}$ & $\begin{array}{l}\text { Invite teachers from both inside and } \\
\text { outside the school to form a team of } \\
\text { instructors. }\end{array}$ & Arrange exhibition \\
\hline
\end{tabular}

Table 1. Environmental Furnishing Design" micro project learning teaching process table

\section{2 "Environmental Furnishing Design" micro-project performance evaluation standard}

\subsubsection{Subject fitness (occupied 20\%):}

A. Excellent 90 points or more:The sub-themes are clearly expressed; the decoration materials and furnishings are used to make the color; the actual situation of the site is met; the theme ideas and design drawings can be expressed accurately and completely, and the expressions are accurate and harmonious; there are a certain number of samples, models or objects.

B. Good 80-90 points: The sub-themes are clearly expressed; the use of decorative materials and furnishings is appropriate; the expression of thematic ideas and design drawings can be expressed accurately and harmoniously. There are a certain number of samples, models or objects.

C. Medium70-80 points:The sub-themes are more explicit; the use of decorative materials and furnishings is more appropriate; the basic ideas can be basically expressed; the design drawings are more complete. There are small samples, models or objects.

D. Bad 70 points or less: The subtopic is not clearly defined; the design drawings are indeed or have serious errors. There are no samples, models or objects.

\subsubsection{Originality (occupied $20 \%$ ):}

A. Excellent 90 points or more:Decorative shape, furnishings material extraction and production belong to the original; expressions of imagination and personality; drawings are novel in form and unique in conception.

B. Good 80-90 points: The most Material extraction extraction and production belong to the original; the most drawings are novel in form and unique in conception.

C. Medium70-80 points: Have some unique idea and expression.

D. Bad 70 points or less: No original.

\subsubsection{Artistry (occupied 20\%):}

A. Excellent 90 points or more: The primary and second versions are vivid or colorful;group members have certain aesthetic ability.

B. Good 80-90 points: The most primary and second versions are vivid or colorful;group members have some aesthetic ability. 
C. Medium70-80 points:The some versions are vivid or colorful;group members have a little bit aesthetic ability.

D. Bad 70 points or less:No aesthetic ability.

\subsubsection{Technicality (occupied 40\%):}

A. Excellent 90 points or more: Accurate and appropriate using art design software and pre-processing on the basis of design;the elements of the primary and second versions are complete.

B. Good 80-90 points: Appropriate using art design software and pre-processing on the basis of design;the elements of the primary and second versions are basically complete.

C. Medium70-80 points: Using art design software and pre-processing on the basis of design; the elements of the primary and second versions are basically complete.

D. Bad 70 points or less:Improper using art design software and pre-processing on the basis of design.

\subsection{The Purpose of Micro Project}

Through the basic knowledge of the previous design, the student jointly design the home entrance space in the form of group cooperation, and the theme can be refined and determined independently, which greatly stimulates students' interest in learning and innovation, and deeply understands the strength and importance of the team.

\section{Conclusion}

Applying micro-project learning to the teaching of furnishings curriculums is in line with the "emergency needs, practice-oriented, and oriented application" ,that is , this type of course characteristics. Combining the professional skills requirements of the furnishings major, set up easy-to-understand and easy-to-complete micro-project tasks in the actual teaching, so that students not only learn the design skills by themselves, but also they can use technology to solve the practical problems, comprehensively cultivate students' ability of independent learning, teamwork, innovation and problem solving.

Projects: 2017, Guangxi Art Institute, Research and Practice Innovation Team of the High-Level Innovation Team Project "Guangxi Native Architectural Features in Contemporary Furnishing Environment Design" (none); 2017, Guangxi Art Institute, Teaching Research and Teaching Reform Incentive Project "Reform and Practice of the Furnishings Curriculum Based on Inheritance of Traditional Architectural Decoration Aesthetics" (2017JGY68)

\section{References}

1. Jin Ling . (2018) Flip the Classroom: The Power of Micro-Project Learning__Reading "the Flip Class Design Strategy Based on Micro-Project Learning”. China Information Technology Education, 8,77.

2. Zhu Canwei, Lu Canju .(2018) Research on the Reform of University Computer Practice Teaching. Software Guide (Education Technology), 1,47. 